\title{
Cognitive societalhuman values of sports: after the 2011 disaster of Japan
}

\author{
SASAKI Koh ${ }_{5}^{1, *}$, Takumi yamamoto ${ }^{2}$, Kayoko Komatsu ${ }^{3}$, Yuichi Ueno ${ }^{4}$, Takashi Katsuta ${ }^{5}$, \\ Ichiro Kono ${ }^{5}$ \\ ${ }^{1}$ Nagoya University, Nagoya, Japan \\ ${ }^{2}$ National Defense Academy, Yokosuka, Japan \\ ${ }^{3}$ Tokyo University of the arts, Tokyo, Japan \\ ${ }^{4}$ Ryutsu keizai University, Ryugasaki, Japan \\ ${ }^{5}$ Tsukuba University, Tsukuba, Japan
}

\section{Email address:}

sasaki@htc.nagoya-u.ac.jp (SASAKI Koh)

\section{To cite this article:}

SASAKI Koh, Takumi yamamoto, Kayoko Komatsu, Yuichi Ueno,Takashi Katsuta, Ichiro Kono. Cognitive Societal Human Values of Sports: after the 2011 Disaster of Japan, Social Sciences. Vol. 2, No. 1, 2013, pp. 1-6. doi: 10.11648/j.ss.20130201.11

\begin{abstract}
This study examines the recognition of life management and offers insight into the interpretation of benevolent sports activities following Japan's March 2011 disaster. After the incident, people suspended all sports activities, but various benevolentsports activities were developed immediately in the damaged areas. By interviewing Japanese students ( $\mathrm{N}=405)$, this descriptive study investigates the recognized human value structure of sports in a crisis situation by applying the social management concept of 'time perspective' and 'hope'. The question asked to the participants was 'What types of values do you recognize in Japanese benevolent sports activities to help the damaged society after the 2011 disaster?' The participants ranked eighteen items (1 to 18 ) terminal and instrumental values. Next, cluster analysis (Ward's method) was carried out to further explore the close relationships between the ordersof intimacyvalues within each value cluster. The results of the terminal values study suggest greatest recognition of (1)a world with the universal values of 'happiness' and 'freedom' and (2) the pursuit of a life with finite values of 'a sense of accomplishment' and 'self-respect'. This clustering suggests the ontological commitmentto a dynamic balance of finite and universal values. The results of the instrumental values study suggest greatest recognition of the following human characteristics: (1) 'courageous' and 'honest' by inner motivation and altruistic dedication to virtue ethics and (2) 'ambitious' and 'capable (of logical activism)' for survival. Finally, a network analysis was performed to explore the centrality of the multi-value space in benevolent sportsactivities. Network analysis (graph theory) presentsthe holistic evaluation method for the positional functions of societal values and organization.
\end{abstract}

Keywords: Human-Values, Sports, Cluster Analysis, Network Analysis

\section{Introduction}

Since the East Japan disaster on 11 March 2011, Japanese society has been losing hope for future. This catastrophe caused people to refrain from all sports activities, even as various benevolent sports activities were immediately acted upon in the damaged areas. National teams and professional leagues held charity matches, along with local supports for life lines by the local clubs' residents through human networking, and various other donation activities. The current study examines the recognized human value structure in sports in this crisis situation by referring to new social management concepts of the 'time perspective study' and 'study of hope'.
The study of hope began in 2000 as a social managerial discussion $[1,2]$. The purpose is to explore not facile optimism but the structure of positive and autonomic thinking and facing the reality of serious stagnation. Human values study is an approach that clarifies cognitive beliefs operating in decision making and dealing with conflict in human life. It would be one of the recognized life management motivations in a crisis situation. The academic positioning of this study is to identify the human value structure in sports for future studies.

As people live amid various complex values, when a value is recognized, it becomes part of a value system in which various values are prioritized. The system has two dimensions, terminal values (end-states of existence) and 
instrumental values (modes of conduct). This study adopted Rokeach's two-value model [3]. Rokeach's model presents practical and clear terminal values items such as 'nation', 'true friendship', 'a sense of accomplishment', 'inner harmony' and 'world peace' as attributed values. The model also presents practical and clear instrumental value items such as 'broadminded' and 'forgiving' as concrete mentality, in addition to 'courageous' and 'honest' as life skills. These holistic cognitive value chain structures for sports activities, including benevolence, would be expected to describe the relationship between success in sport and survival in society. For a discussion on human values, the study of hope or time perspective as a life management approach and the study of terror management [4] as biological ontology would be effective. From these viewpoints, this study discusses the value chain of ontological commitment to society's realistic survival.

\section{Methods}

Rokeach's model orders the priority of the various values of each of the 18 items of terminal and instrumental values and has a time perspective appearance value structure. For example, 'nation' and 'world peace' would be enumerated at a comparatively higher grade during a serious conflict situation between nations. According to Japan's current social conditions, the authors made several changes in this study from Rokeach's initial items. In terminal values, the authors changed 'national security' (protection from attack) to 'national unity' to mean the consensus of the willingness of the citizens. 'World beauty' (beauty of nature and arts) was changed to 'world beauty (beauty of human beings and nature). In instrumental values, 'obedient' (dutiful, respectful) was changed to 'respectful' (dutiful) to mean proactive willingness rather than passive willingness.

Subjects were university students $(\mathrm{N}=405$ : male $=257$, female $=148$ : age $=18-23$, Avg. $=20.0$; faculty: Social science (Literature, Education, Law) $=202$, Natural science $($ Engineering $)=203$; date $=$ June-July 2011). Students were explained the study structure and various benevolent activities of sports such as donations, the charity matches and the voluntary rescue activities. Next, students were asked, 'What types of values do you recognize in Japanese benevolent sports activities to help the damaged society after the 2011 disaster?' They were then asked to rank the eighteen items ( 1 to 18 ) of terminal and instrumental values. In the item ordering, the items were given $18-1$ points (the highest ordered value received 18 points, the second one 17 points and so on). Next, we performed cluster analysis (Ward's method) to further explore the close relationships between the orders of intimacy values within each value cluster. To understand the comprehensive human values in life, their free description would be required, but the ranking of values and the order relationships can clarify the latent value structure. This issue is the limitation of this study's approach. Finally, a network analysis was performed to explore the centrality of the multi-values space in benevolent sports activities.

\section{Result and Discussion}

\subsection{Terminal Values}

The priority order of terminal values was 'happiness (contentedness)', 'a sense of accomplishment (lasting contribution)', 'freedom (independence, free choice)', 'true friendship (close companionship)', 'inner harmony (freedom from inner conflict)', 'family (taking care of loved ones)', 'world peace (free from war and conflict)', 'equality (brotherhood, equal opportunity for all)', 'a comfortable life (a prosperous life)', 'world beauty (beauty of human and nature)', 'an exciting life (a stimulating, active life)', 'self-respect (self-esteem)', 'wisdom (a mature understanding of life)', 'social recognition (respect, admiration)', 'mature love (spiritual intimacy)', 'pleasure (an enjoyable life)', 'salvation (eternal dedication)', 'national unity (consensus for one country)' (Figure 1). 'A sense of accomplishment', which was ranked at the second place in this study, was ranked first in a past study[5] concerning sport challenging values performed just before the 2011 disaster, comparing universal values about sports activities. 'Happiness' and 'freedom', which were ranked at the first place and third place in this study, were ranked lower in the earlier study $^{5}$. In the present study, 'happiness' rose from the seventh to first place, and 'freedom' rose from the fifteenth to second place. These changes are discussed in the cluster analysis below. An analysis of Variance (ANOVA) and Scheffe's Least Significant Difference (LSD) test were used to clarify the 18 values' order differences. A significant main effect was found for the value order $(\mathrm{N}=405, \mathrm{df}=17, \mathrm{~F}=$ 88.7, $\mathrm{p}<0.01)$. Scheffe's LSD tests also indicated many significant differences between values (Table 1).
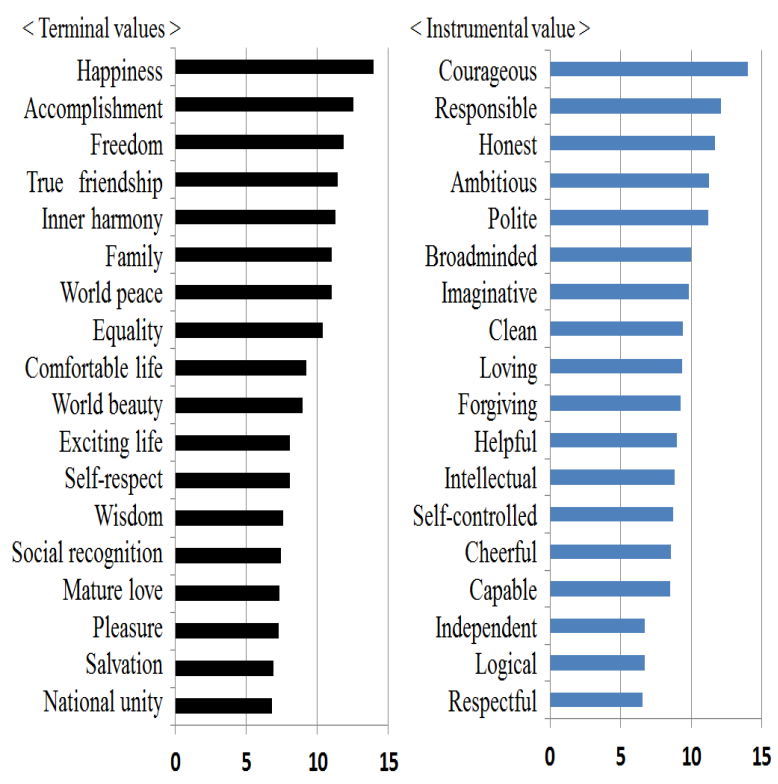

Figure 1. Recognized orders terminal and instrumental values for benevolent sports activities after the 2011 disaster in Japan $(N=405)$. 
Table 1. Scheffe's Least Significant Difference (LSD) test to clarify the difference in the orders of the 18 terminal values. $\left(* *=p<0.01:^{*}=p<0.05\right)$.

\begin{tabular}{|c|c|c|c|c|c|c|c|c|c|c|c|c|c|c|c|c|c|c|}
\hline & $\begin{array}{c}\text { Happi- } \\
\text { ness }\end{array}$ & \begin{tabular}{|l} 
Accomp- \\
lishment
\end{tabular} & Freedom & $\begin{array}{c}\text { True } \\
\text { friendship }\end{array}$ & $\begin{array}{c}\text { inner } \\
\text { hamony }\end{array}$ & family & $\begin{array}{l}\text { World } \\
\text { peace }\end{array}$ & Equality & \begin{tabular}{|c|} 
Comfort \\
able life
\end{tabular} & $\begin{array}{l}\text { World } \\
\text { beauty }\end{array}$ & $\begin{array}{l}\text { Exciting } \\
\text { life }\end{array}$ & $\begin{array}{c}\text { Self- } \\
\text { respect }\end{array}$ & Wisdom & \begin{tabular}{|} 
Social re- \\
cognition
\end{tabular} & $\begin{array}{c}\text { Mature } \\
\text { love }\end{array}$ & pleasure & Salvation & $\begin{array}{c}\text { National } \\
\text { unity }\end{array}$ \\
\hline Happiness & 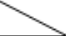 & ** & $* *$ & ** & ** & ** & $* *$ & ** & ** & ** & ** & ** & ** & ** & ** & ** & ** & ** \\
\hline Accomplishment & & 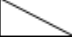 & * & ** & ** & ** & ** & ** & ** & ** & $* *$ & ** & ** & ** & ** & ** & ** & $* *$ \\
\hline Freedom & & & $>$ & & & $*$ & $*$ & $* *$ & $* *$ & $* *$ & ** & ** & ** & ** & ** & ** & ** & ** \\
\hline True friendship & & & & 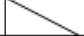 & & & & ** & ** & ** & $* *$ & ** & ** & ** & ** & ** & ** & $* *$ \\
\hline inner harmony & & & & & $\infty$ & & & $* *$ & $* *$ & *** & ** & ** & ** & $* *$ & ** & ** & ** & ** \\
\hline family & & & & & & 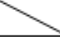 & & & ** & *** & ** & ** & ** & ** & ** & ** & ** & ** \\
\hline World peace & & & & & & & 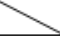 & & ** & *** & ** & ** & ** & ** & ** & ** & $* *$ & ** \\
\hline Equality & & & & & & & & 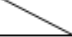 & ** & *** & ** & ** & ** & ** & ** & ** & ** & ** \\
\hline Comfortable life & & & & & & & & & 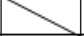 & & ** & ** & ** & ** & $* *$ & ** & ** & $* *$ \\
\hline World beauty & & & & & & & & & & 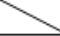 & ** & ** & ** & *** & ** & ** & ** & ** \\
\hline Exciting life & & & & & & & & & & & 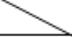 & & & $*$ & $*$ & $*$ & ** & $* *$ \\
\hline Self-respect & & & & & & & & & & & & 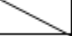 & & & $*$ & $*$ & ** & *** \\
\hline Wisdom & & & & & & & & & & & & & 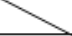 & & & & $*$ & $*$ \\
\hline \multicolumn{19}{|l|}{ Social recognition } \\
\hline \multicolumn{19}{|l|}{ Mature love } \\
\hline \multicolumn{19}{|l|}{ pleasure } \\
\hline \multicolumn{19}{|l|}{ Salvation } \\
\hline National unity & & & & & & & & & & & & & & & & & & 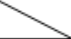 \\
\hline
\end{tabular}

\subsection{Instrumental Values}

The priority ranking order for instrumental values was 'courageous (standing up for your beliefs)', 'responsible (dependable)', 'honest (sincere, truthful)', ambitious (hard-working, aspiring)', 'polite (courteous)', 'broadminded (open-minded)', 'imaginative (creative)', 'clean (neat)', 'loving (affectionate)', 'forgiving (willing to pardon others)', 'helpful (welfare for others)', 'intellectual (intelligent)', 'self-controlled (self-disciplined)', 'cheerful (lighthearted, joyful)', 'capable (competent, effective)', 'independent (self-reliant)', 'logical (consistent)', 'respectful
(dutiful)'(Figure 1). The top four values of 'courageous', 'responsible', 'honest' and ambitious' were also ranked in the top five values in the past study ${ }^{5}$. An analysis of variance (ANOVA) and Scheffe's Least Significant Difference (LSD) test were used to clarify the 18 values' order differences. Our past study[5] also reported that 'courageous', 'responsible' and 'honest' were ranked amongst the top five sports values before the 2011 disaster. A significant main effect was found for the value order $(\mathrm{N}=405, \mathrm{df}=17, \mathrm{~F}=68.2, \mathrm{p}<0.01)$. Scheffe's LSD tests also indicated many significant differences between values (Table 2).

Table 2. Scheffe's Least Significant Difference (LSD) test to clarify the order difference of the 18 instrumental values. $(* *=p<0.01: *=p<0.05)$.

\begin{tabular}{|c|c|c|c|c|c|c|c|c|c|c|c|c|c|c|c|c|c|c|}
\hline & $\begin{array}{c}\text { Courage- } \\
\text { ous }\end{array}$ & $\begin{array}{c}\text { Respons- } \\
\text { ible } \\
\end{array}$ & Honest & $\begin{array}{l}\text { Ambi- } \\
\text { tious }\end{array}$ & Polite & $\begin{array}{l}\text { Broad- } \\
\text { minded }\end{array}$ & $\begin{array}{l}\text { Imagi- } \\
\text { native }\end{array}$ & Clean & Loving & $\begin{array}{c}\text { Forgiv- } \\
\text { ing }\end{array}$ & Helpful & \begin{tabular}{|c} 
Intellect- \\
ual \\
\end{tabular} & $\left|\begin{array}{c}\text { Self- } \\
\text { controlled }\end{array}\right|$ & Cheerful & Capable & $\begin{array}{c}\text { Indepen- } \\
\text { dent }\end{array}$ & Logical & \begin{tabular}{|c} 
Respec- \\
tful
\end{tabular} \\
\hline Courageous & - & * & ** & ** & ** & ** & ** & ** & ** & ** & ** & ** & ** & ** & ** & ** & ** & $* *$ \\
\hline Responsible & & 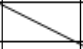 & & & & $* *$ & $* *$ & $* *$ & $* *$ & $* *$ & $* *$ & $* *$ & ** & ** & $* *$ & $* *$ & $* *$ & $* *$ \\
\hline Honest & & & 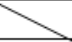 & & & & $*$ & $* *$ & ** & $* *$ & ** & $* *$ & ** & ** & ** & ** & ** & $* *$ \\
\hline Ambitious & & & & 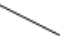 & & & & $*$ & * & ** & ** & ** & ** & ** & ** & ** & ** & ** \\
\hline Polite & & & & & $>$ & & & & * & $* *$ & ** & $* *$ & ** & $* *$ & ** & $* *$ & $* *$ & $* *$ \\
\hline Broadminded & & & & & & $>$ & & & & & & & & & & $* *$ & ** & $* *$ \\
\hline Imaginative & & & & & & & 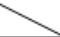 & & & & & & & & & ** & ** & ** \\
\hline Clean & & & & & & & & $x$ & & & & & & & & $* *$ & $* *$ & $* *$ \\
\hline Loving & & & & & & & & & 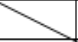 & & & & & & & $* *$ & ** & $* *$ \\
\hline Forgiving & & & & & & & & & & 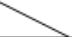 & & & & & & ** & ** & ** \\
\hline Helpful & & & & & & & & & & & $x$ & & & & & $* *$ & $* *$ & $* *$ \\
\hline Intellectual & & & & & & & & & & & & 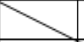 & & & & $* *$ & ** & $* *$ \\
\hline Self-controlled & & & & & & & & & & & & & $>$ & & & $* *$ & $* *$ & $* *$ \\
\hline Cheerful & & & & & & & & & & & & & & $>$ & & * & $*$ & $* *$ \\
\hline Capable & & & & & & & & & & & & & & & 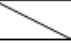 & $*$ & $*$ & $* *$ \\
\hline \multicolumn{19}{|l|}{ Independent } \\
\hline \multicolumn{19}{|l|}{ Logical } \\
\hline Respectful & & & & & & & & & & & & & & & & & & $\gamma$ \\
\hline
\end{tabular}




\subsection{Cluster Analysis (Ward's Method)}

\subsubsection{Terminal Values 1: Cluster Based on the First Priority Value, 'Happiness'}

Students answered that 'happiness' was the first priority value for benevolent sports in 2011, and it was positioned closely with 'freedom', the third priority ordered value. (Figure 2) However, we cannot determine whether students can actually feel the sufficiency of desire. Paradoxically, people might recognize the feeling of insufficiency of happiness and freedom after the 2011 disaster. As demonstrated in the values order results, these two were ranked higher than in the past study [5] before the 2011 disaster. The meaning of 'happiness' includes contentedness, and 'freedom' includes no restriction of action opportunities. These comparatively abstract meanings can be interpreted more comprehensively with the next closest positioned value items. 'Happiness' and 'freedom' were positioned closely with 'true friendship', 'family', 'inner harmony' and 'mature love'. These were positioned as an intimacy values. Happiness and freedom in sport might be recognized as producing inner harmony with close human proximity to taking care of others. 'Family' is the most affective value item in other studies of hope $[6,7]$. The succeeding closed values, which were 'world peace', 'world beauty', 'salvation' and 'national unity', might be expected when border wars cause people to long for a stable world. 'Happiness' and 'freedom' in sport were suggested as being built by connecting by human intimacy in the world and the nation after the 2011 disaster. These values comprised the first cluster in the cluster analysis. In the concreteness of sports along universal and centripetal axes might be recognized. The recognition of happiness would be a positive time focused perspective [2].

From the other academic viewpoint, the biological facts state that recognized memories remain in existence even though human brain cells are constantly regenerated [6]. From this perspective, the study of values concerning a hope or a time perspective can be discussed with the study of the biology of working memory, which may be called 'bio-sociology'. Even if today's memory were terribly painful, human memory could learn to overcome it and come to think of it positively as an opportunity, maintaining the memory of one's own belief in the future ${ }^{2}$. Human beings could exist in a dynamic equilibrium to adapt to the societal environment [8].

However, in the priority ordered values of this study, 'salvation' and 'national unity' in this cluster, were ranked comparatively lower (Figure 2) than in the previous study ${ }^{5}$. This result might suggest that tremendous impact of this disaster destroyed the recognized values of 'salvation' or 'national unity' in Japan.

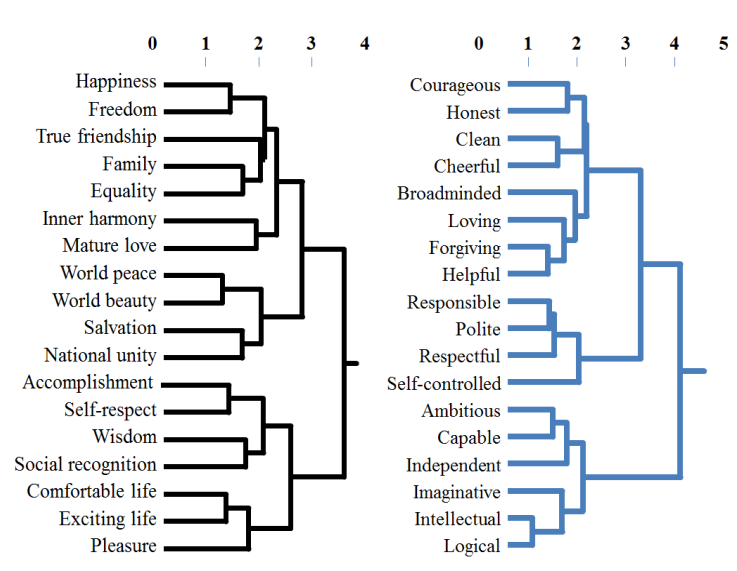

Figure 2. Clustered terminal and instrumental values for benevolent sports activities after the 2011 disaster in Japan $(N=405)$.

\subsubsection{Terminal Values 2:Cluster Based on the Second Priority Value, 'Accomplishment'}

Students responded that 'a sense of accomplishment (lasting contribution)' was the second-ranked priority value as benevolent sport in 2011. This response reflects the benchmark and performance element in sport challenges. Competence performance for survival in today's severe competitive situation might be carried out by the practical action of making lasting contributions. Would such practical and concrete action be needed in Japanese society? In cluster analysis, 'a sense of accomplishment' was positioned most closely to 'self-respect', which implied facing oneself and believing in one's own potential, and next most closely positioned to 'wisdom' and 'social recognition', which rationalize social existence with succeeding in competition. These values might suggest today's sport competencies of severity and ontology. The next closest values to 'accomplishment' were 'a comfortable life', 'an exciting life' and 'pleasure', which concern socio-psychological health status.

Sport has a characteristic of pursuing the limits of the body's ability. The reason for human beings to take on challenges throughout history and remain in existence might be related to the concept that finite life is closely related to some form of infinite cultural mind (e.g. universalism of values) $[9,10]$. Humankind could be meeting challenges and making lasting contributions with a compound value structure subsumed by practical wisdom and cultural existence as terror management skills. As we have mentioned, this phenomenon could be interpreted as the socio-biological existence of dynamic equilibrium. Human existence could reflect a dynamic balance of both biological and ontological values, such that humankind lives with not only one value but also freely selected and compounded multi-values to adapt to an increasingly complex environment and society. In that context, the values recognized in sports might have common ontological commitments.

\subsubsection{Instrumental Values 1: Cluster Based on the First Priority Value, 'Courageous"}


The ranking of 'courageous (standing up for one's belief)' as the first priority value of sports suggested the fortitude characteristic of severe competence opportunity. Furthermore 'courageous' was closely positioned with 'honest (sincere, truthful)', which is the third priority value (Figure 2). The internally motivated value of 'courageous' connects logically with self-effacement in the 'honest' value. The next closest values were 'clean (neat)' and 'cheerful (lighthearted, joyful)'. These four items involve positive inner-directed drive, including enterprise and decisiveness [10]. Those values in turn expand the connection to the next four closest values of 'forgiving (willing to pardon others)', 'helpful (welfare for others)', 'loving (affectionate)' and 'broadminded (open-minded)', which are comparatively outer-directed compassion for others [9]. These accumulated values derived from 'courageous' were closest to the second ranked priority 'responsible' and 'polite' ( $4^{\text {th }}$ place $)$, 'respectful' ( $18^{\text {th }}$ place) and 'self-controlled' $\left(13^{\text {th }}\right.$ place $)$. This cluster of altruistic dedication with temperance might be considered virtue ethics ${ }^{11}$ and bio-sociological survival values for the selection of the fittest.

\subsubsection{Instrumental Values 2: Cluster Based on the Fourth Priority Value, 'Ambitious'}

'Ambitious' was closest to 'capable' and 'independent', and next closest to 'logical', 'intellectual' and imaginative'. These formed a markedly different value group from the first group. The cluster implies human activism through unflagging pursuit of practical capability with the logic and intelligence necessary for survival. However, when people suffer a serious catastrophe, they may experience more anxiety about their capability. Societal human values evolve as a long-term trend in culture throughout history[7], but they might be also affected by emergent short-term factors such as serious disasters.

\subsection{Network Analysis}

Network analysis has been developed in communication-network studies as a graphic representation theory of mathematics studies. A network has structures of the vertex (societal value) and the edge line (relation), and thus, network analysis presents a descriptive index of the graph structure and statistics.

To understand the relation structure of the $18^{\text {th }}$ ordered societal values, we plotted the correlation coefficients in the adjacent matrix (36x36), and we calculated the degree centrality (numbers on the edge line) and eigenvector centrality [12]. The calculation and networking map-making were performed by the computer program tool 'igraph' of ' $R$ ' developed the authors. We applied the Jaccard's coefficient weighting for the intersection divided by the sample sets.

$$
J(A, B)=\frac{|A \cap B|}{|A \cup B|}
$$

Degree means the frequency of links incident upon a societal value (vertex) and calculated for all the vertexes in an adjacency matrix. The network map was made by the degree centrality of a vertex ' $v$ '. Degree centrality is as follows:

$$
C_{D}=\frac{\sum_{i=1}^{V}\left[C_{D}(v *)-C_{D}\left(v_{i}\right)\right]}{(\mathrm{n}-1)(\mathrm{n}-2)}
$$

$C_{D}$ : degree centrality, $\quad v *$ : vertex with highest degree centrality, $v_{i}$ : actual degree centrality, i: vertex number, $\mathrm{V}$ : total vertices, $(n-1)(n-2)$ : max value when the graph contains one central vertex to which all other vertexes are connected (a star graph).

The map layout (Figure 3) was calculated by the Fruchterman-Reingold Algorithm [13], which is a force-directed layout algorithm for centralization of the societal values' positioning. The purpose was to position the vertexes of a graph in two-dimensional space so that all the edges were of more or less equal length and there were as few crossing edges as possible $[14,15,16]$.The force-directed algorithms achieved this by assigning forces among the set of vertexes and the set of edges. The forces were applied to the vertexes, pulling them closer together or pushing them further apart. This was repeated iteratively until the system comes to an equilibrium state.Main value network contributors that mapped centrally in the graph were 'happiness', 'inner harmony', 'accomplishment', 'courageous', 'true friendship and 'broadminded'. These six values might construct the primitive ontology or behavioral mission and might represent the abstract of ordering values or clustering values. By using centrality indices, the network analysis (graph theory) presents the holistic evaluation method for the positional functions of societal values and organization. It also presents strategic and tactical information for planning and communications on the basis of those values with centrality in managing real activities. For example, in Figure 3, from the vertical arrows that connect 'self-controlled' and 'inner harmony' to 'happiness' and 'freedom', one can observe the balance structure between self-constraint and self-liberation. From the horizontal arrows that connect 'logical', 'accomplishment' and 'courageous' to 'true friendship', 'honest' and 'world peace', one can observe the balance structure between competitive advantage and bond of world.

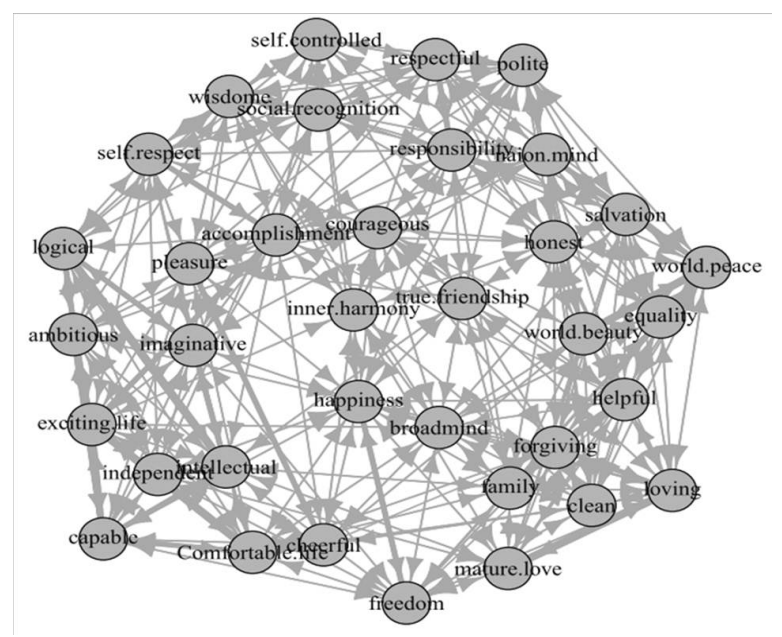

Figure 3. Mapping of societal human values of benevolent sports activities after the 2011 disaster by force-directed placement (degree centrality). 


\section{Conclusion}

This study of values examined the recognition of life management and offered insight into the effects of benevolent sports activities following Japan's March 2011 disaster. The study of terminal values suggested greatest recognition of (1) a world with the universal values of 'happiness' and 'freedom' and (2) the pursuit of a life with the finite values of 'a sense of accomplishment' and 'self-respect'. This clustering suggested that the human being exist in a dynamic balance of finite and universal values. The study of instrumental values suggested the greatest recognition of the following human characteristics: (1) 'courageous' and 'honest' by inner motivation and altruistic dedication for virtue ethics and (2) 'ambitious' and 'capable (of logical activism)' for survival. One may concluded that sports represent unique practical values in human life. Network analysis further suggested that certain centrality values might be plotted for understanding the complex societal value space. Human existence could reflect a dynamic balance of both biological and ontological values such that humankind lives with not only one value but also freely selected and compounded multi-values to adapt to an increasingly complex environment and society. In that context, the values recognized in sports might have common ontological commitments.

The tremendous disaster would naturally affect the societal values structure. However, when the society considers the time perspective facts not only as heteronomous but also as autonomous and with hope, the societal human values may be transformed into preferred action criteria for the future. If benevolent sports activities promote and consolidate the shared positive ontological values, these bio-sociological activities could be one key factor in recovering from the disaster and continuing toward the future. Further analysis may clarify for sports ontological values by cross-disciplinary research.

\section{Acknowledgements}

This study was partly supported by JSPS KAKENHI grant Number 24500736 and the Sport Management Committee of the Japanese Society of Physical Education, 2011. The authors would also like to thank Enago (www.enago.jp) for the English language review.

\section{References}

[1] Y. Genda, Y., "Social sciences of hope," Tokyo University Press. Japan, 2009.

[2] M. Tsuzuki, "Study of hope," Minerva Shobo. Japan, 2004.

[3] M. Rokeach, "The nature of human values," the free press, 1973.

[4] D. L. Paulhus, and P. D. Trapnell, "Terror management theory: extended or overextended?" Psychological injury, 8(1), pp.40-43, 1997.

[5] K. Sasaki,K, Descriptive societal-value structure and mapping approach on football: soccer \& rugby union, 7th world congress on science \& football, (Nagoya University, Japan) 2011.

[6] R. Layared, "Happiness," The Penguin Press, 2005.

[7] Japanese House of Councilors, "Research paper of happiness," 2009.

[8] S. Fukuoka, “Dynamic equilibrium,"Kirakusya Japan, 2009.

[9] H. S. Schwarts, "Universals in the content and structure of values: theoretical advances and empirical tests in 20 countries," Advance in experimental social psychology, 25, pp.1-65, 1992.

[10] H. S. Schwartz, and W. Bilsky, "Toward a universal psychological structure of human values," Journal of Personality and Social Psychology, 53(3), pp.550-562, 1987.

[11] B. Loi,“Resolving ethical dilemmas,” Lippincott Williams \& Wilkins Inc.,2000.

[12] P. Bonacich, andP. Lloyd, "Calculating status with negative relations,"Social networks, 26, pp.331-338, 2004.

[13] T. M. J. Fruchterman, and E. M. Reingold, "Graph Drawing by Force-directedPlacement,"Software - Practice and Experience, 21(11), pp.1129-1164, 1991.

[14] P. Eades, “A Heuristic for Graph Drawing," CongressusNumerantium,42(11), pp.149-160, 1984.

[15] T. Kamada,and S. Kawai, "An algorithm for drawing general undirected graphs," Information Processing Letters(Elsevier) 31(1), pp.7-15, 1989.

[16] K. Inoue, S. Shimozono, H. Yoshida,and H. Kurata, “Application of Approximate Pattern Matching in Two Dimensional Spaces to Grid Layout for Biochemical Network Maps,’PLoS ONE, 7(6): e37739, 2012. 